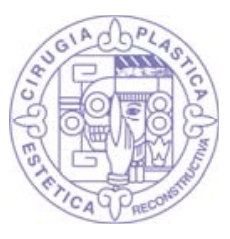

\title{
Salvamento de extremidad superior mediante colgajo dorso-epigástrico
}

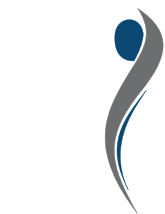

\author{
Superior limb salvage using a dorsal epigastric flap \\ Dr. Jesús Fernando Romero Espinosa,* Dr. Mauro Alonso Lozada Salgado,** \\ Dr. José Fernando Rogel Rodríguez,*** Dr. Fernando Franco Cravioto***
}

Palabras clave: Brazo, miembro superior proximal, colgajo dorsoepigástrico, cobertura cutánea, reconstrucción.

Key words: Arm, proximal superior limb, dorsal-epigastric flap, skin cover, reconstruction.

* Jefe de Servicio.

** Médico adscrito.

*** Médico Residente.

Servicio de

Cirugía Plástica y

Reconstructiva. Centro

Médico «Lic. Adolfo

López Mateos», Instituto

de Salud del Estado de

México.

Los autores de este artículo no tienen conflicto de intereses qué declarar.

Recibido:

3 abril 2018

Aceptado para publicar:

1 agosto 2018

\section{RESUMEN}

La reconstrucción proximal de la extremidad superior es un tema expuesto pocas veces, ya que rara vez se discuten las opciones quirúrgicas disponibles para su salvamento. Presentamos el caso de una mujer con trauma en el brazo que requirió revascularización de la extremidad y cobertura cutánea, proporcionada por un colgajo dorso-epigástrico, logrando el rescate de la extremidad superior con un buen resultado. Concluimos que el uso del colgajo dorsoepigástrico es una opción viable para la reconstrucción de la cubierta cutánea de la extremidad superior proximal y no debe pasar desapercibido.

\section{ABSTRACT}

Proximal reconstruction of the upper extremity is a rarely discussed topic, as the surgical options available for salvage are rarely discussed. We present the case of a woman with trauma to the arm who required revascularization of the limb and skin coverage, provided by a dorsal-epigastric flap, achieving the rescue of the upper extremity with a good result. We conclude that the use of the dorsal-epigastric flap is a viable option for the reconstruction of the cutaneous covering of the proximal upper extremity and should not go unnoticed.

\section{INTRODUCCIÓN}

$\mathrm{L}$ a reconstrucción del miembro superior proximal se describe con muy poca frecuencia en la literatura de la cirugía reconstructiva. Reviste vital importancia el abordar de manera oportuna y sistematizada el trauma de la extremidad superior para preservar la extremidad y sus funciones.

Un algoritmo propuesto por Panattoni, ${ }^{1}$ afronta el trauma de la extremidad superior de manera sistemática, de acuerdo con prioridades y las respectivas opciones disponibles en cada etapa del tratamiento:

a. Evaluación (assessment): desbridar, evaluar vascularidad, revascularizar, realizar fasciotomías, terapia de presión negativa.

b. Hueso (bone): fijación externa, reducción abierta con fijación interna, acortamiento óseo, colgajo o injerto óseo, espaciadores temporales.

c. Contracción de tendones (contraction): reparación tendinosa, injerto, transferencia, tenodesis. d. Denervación (denervation): reparación nerviosa primaria, injerto (aloinjerto, autoinjerto), conductos nerviosos, neurotización.

e. Cobertura (envelope): reparación cutánea primaria, injerto, colgajo local, colgajo libre, sustitutos cutáneos, terapia de presión negativa.

De acuerdo con lo anterior, una vez resueltas las prioridades que incluyen la evaluación, hueso, contracción y denervación, encontramos, dentro de las opciones de colgajos pediculados para brindar un manejo definitivo de la cubierta cutánea, el colgajo dorso-epigástrico, descrito por Haddad, ${ }^{2}$ que es una variante del colgajo de músculo dorsal ancho basado en la rama descendente de la arteria toracodorsal, rama de la subescapular (Figura 1). Toma como puntos de referencia la línea media posterior, el ángulo inferior de la escápula y el borde lateral del músculo dorsal ancho. Se identifica la emisión de las ramas perforantes a $10 \mathrm{~cm}$ por debajo de la axila y $2 \mathrm{~cm}$ por dentro del borde lateral del dorsal ancho, trazando una 
isla cutánea fusiforme y transversa por debajo del ángulo de la escápula hasta la región epigástrica, por debajo del surco inframamario (Figura 2). Representa una herramienta útil que permite dar cobertura cutánea y aumento de volumen en la región torácica, comúnmente utilizado para reconstrucción mamaria, que, sin embargo, posee un pedículo que permite su movimiento hasta la porción proximal del brazo e incluso el cuello.

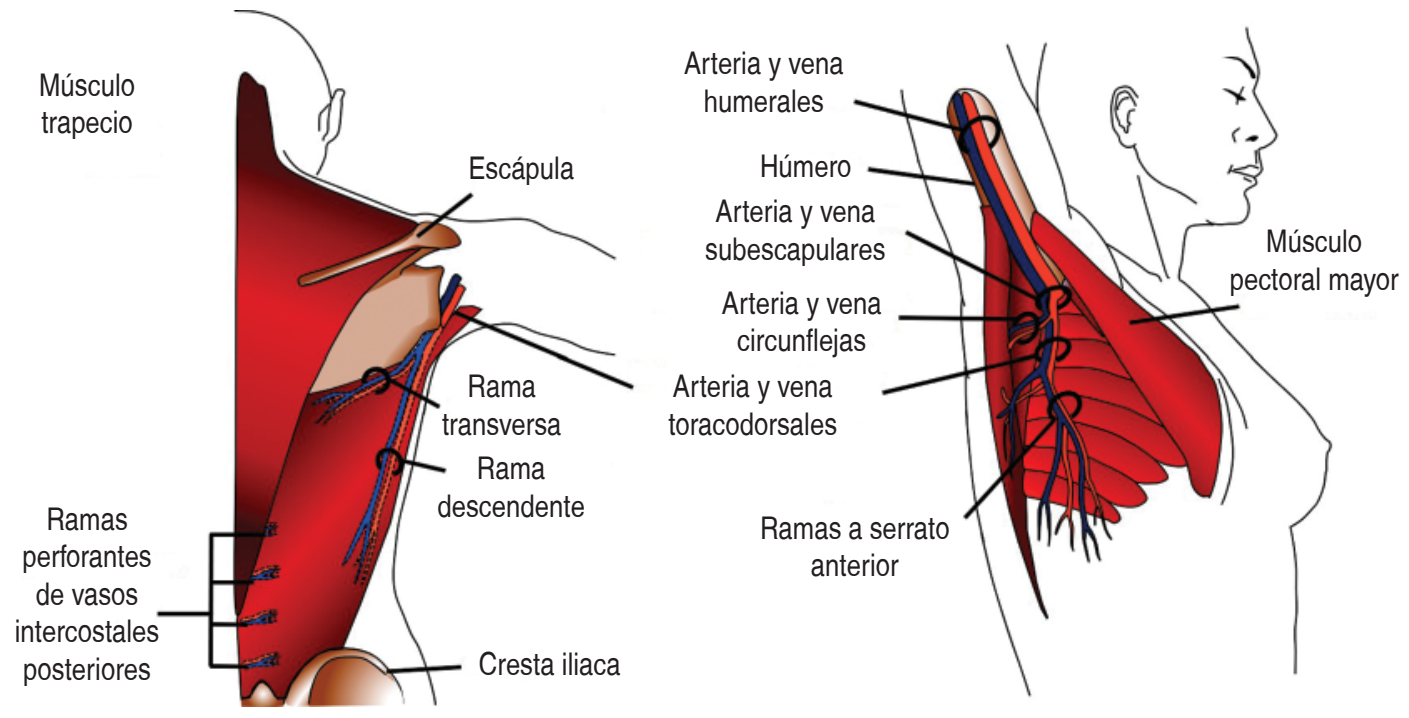

Figura 1. Irrigación del músculo dorsal ancho por la arteria toracodorsal y ramas perforantes de los vasos intercostales posteriores. División del pedículo en una rama transversa y otra descendente, de la cual se emiten perforantes en las que se basa el colgajo dorso-epigástrico.

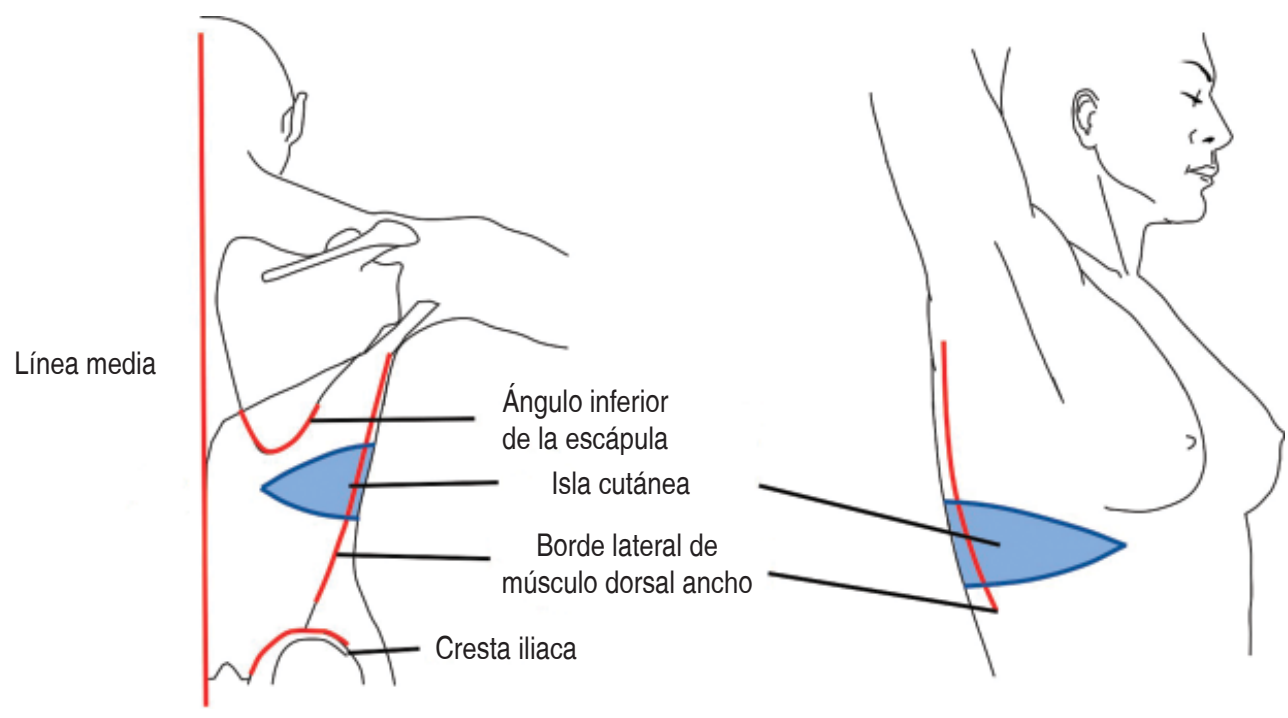

Figura 2. Marcado del colgajo dorso-epigástrico como lo describió Haddad, con isla cutánea transversa por debajo del ángulo inferior de la escápula hasta la región epigástrica por debajo del surco inframamario, incluyendo las perforantes de la rama descendente de la arteria toracodorsal a $10 \mathrm{~cm}$ por debajo de la axila y $2 \mathrm{~cm}$ por dentro del borde lateral del músculo dorsal ancho. 
La utilización del colgajo dorso-epigástrico para reconstrucción de defectos de cobertura en el miembro superior no ha sido reportada en la literatura mundial como una opción, a pesar de su baja morbilidad y su aceptable resultado cosmético.

El objetivo de este trabajo es reportar la utilización del colgajo dorso-epigástrico como una opción para la cobertura del brazo en el salvamento de la extremidad superior por lesión traumática.

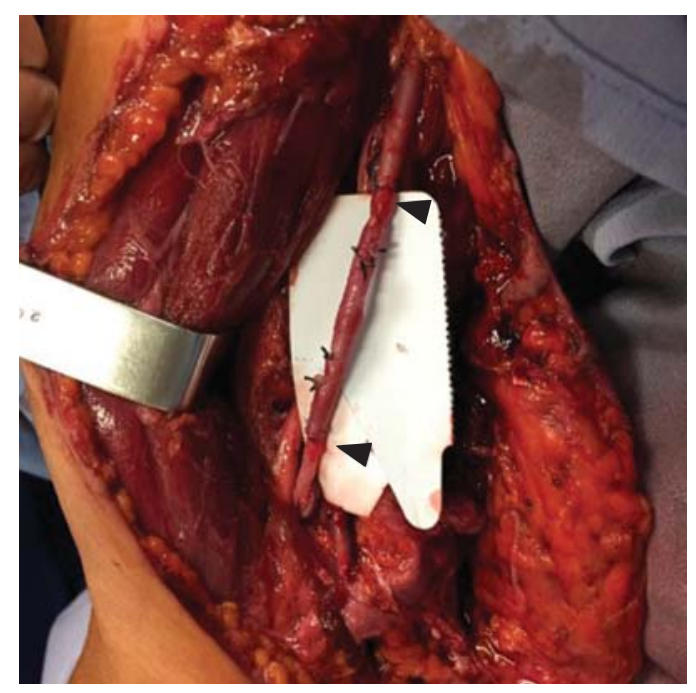

Figura 3. Reparación de la arteria humeral mediante injerto de vena cefálica reversa. Se observa anastomosis (flechas) que irriga a la extremidad.

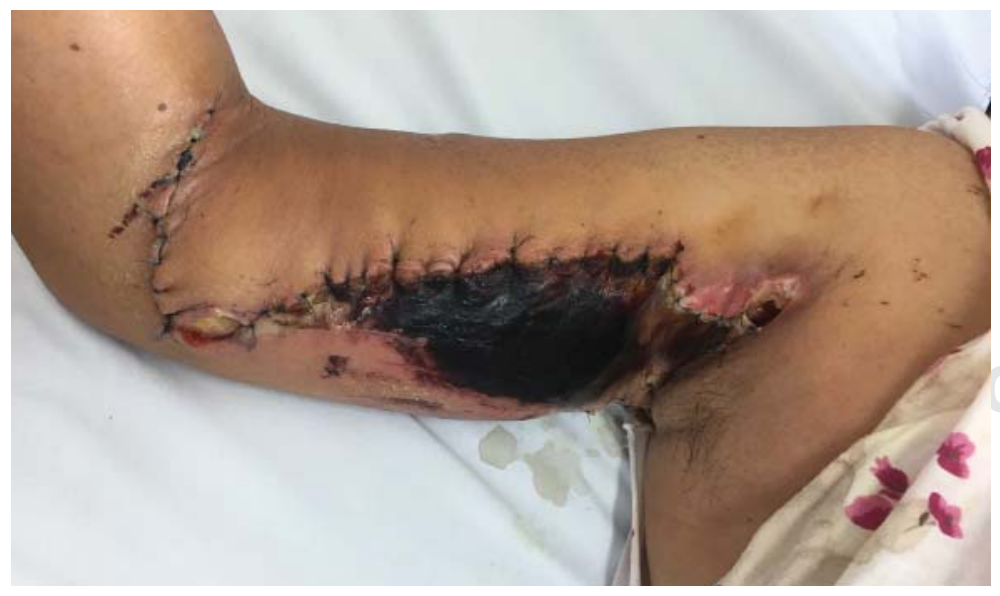

Figura 4. Necrosis de colgajo cutáneo del brazo derecho con anastomosis y paquete neurovascular subyacente.

\section{CASO CLÍNICO}

Mujer de 53 años de edad quien sufrió accidente automovilístico y se presentó en el Servicio de Urgencias con palidez franca de tegumentos y herida en la superficie medial del brazo derecho de $14 \times 8 \mathrm{~cm}$, con sección de la arteria humeral y brecha de $10 \mathrm{~cm}$, por lo que se intervino de urgencia efectuando revascularización de la extremidad superior con injerto venoso reverso y cierre primario (Figura 3), presentando necrosis de la cubierta cutánea (Figura 4), por lo anterior, el riesgo de exposición de elementos nobles y previo consentimiento informado por escrito, se propuso como única alternativa la cobertura mediante colgajo musculocutáneo, utilizando la técnica original descrita por Haddad, marcando el colgajo mediante referencias anatómicas (Figuras 2 y 5), sin utilizar Doppler vascular. Se levantó el colgajo con identificación transquirúrgica del pedículo vascular, tunelizando el colgajo de músculo dorsal ancho con isla cutánea transversa hacia el sitio receptor, corroborando la vitalidad del colgajo. Se colocó drenaje cerrado en el sitio receptor (Figuras 6 a 9), mismo que se retiró al tercer día al ser egresada a su domicilio (Figuras 10 A, C y E), sin presentar complicación alguna en el periodo postoperatorio inmediato o mediato. En su seguimiento en la consulta externa

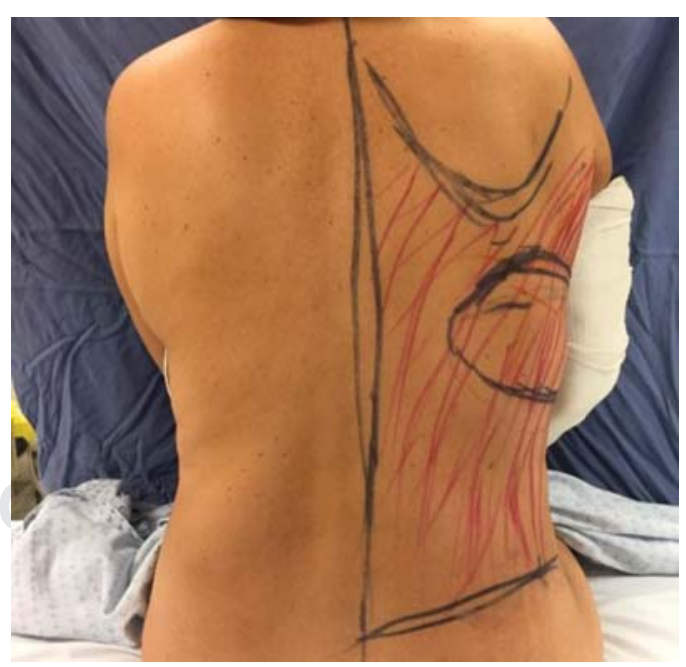

Figura 5. Puntos de referencia para marcado del colgajo: ángulo inferior de la escápula, borde lateral del músculo dorsal ancho, línea media y cresta iliaca. 
a los seis meses (Figuras 10 B, D y F) se observó discreta retracción en la región axilar, por lo que se propuso un procedimiento correctivo, que no fue aceptado por la paciente por no considerarlo como un déficit funcional significativo.

\section{DISCUSIÓN}

La cobertura de tejidos blandos es crucial para la protección del hueso, articulaciones,

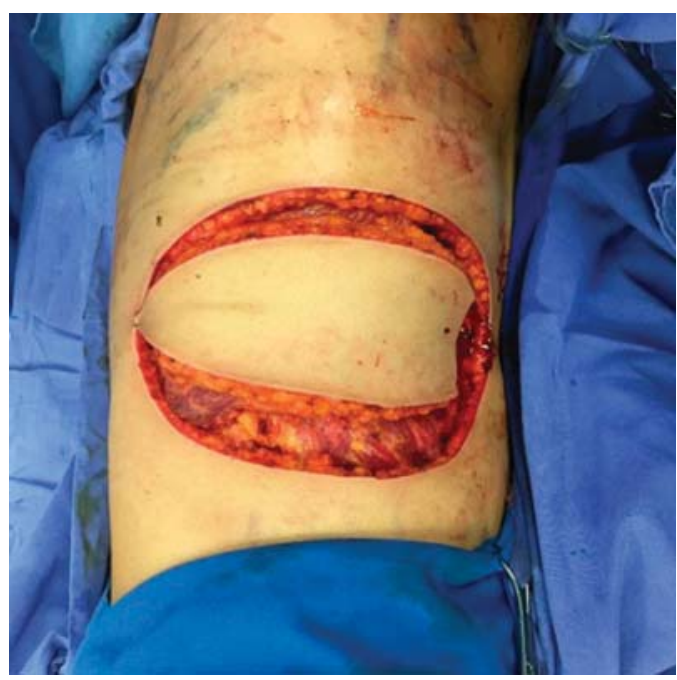

Figura 6. Levantamiento de la isla de piel trazada transversalmente desde la región dorsal hasta la pared anterolateral del abdomen.

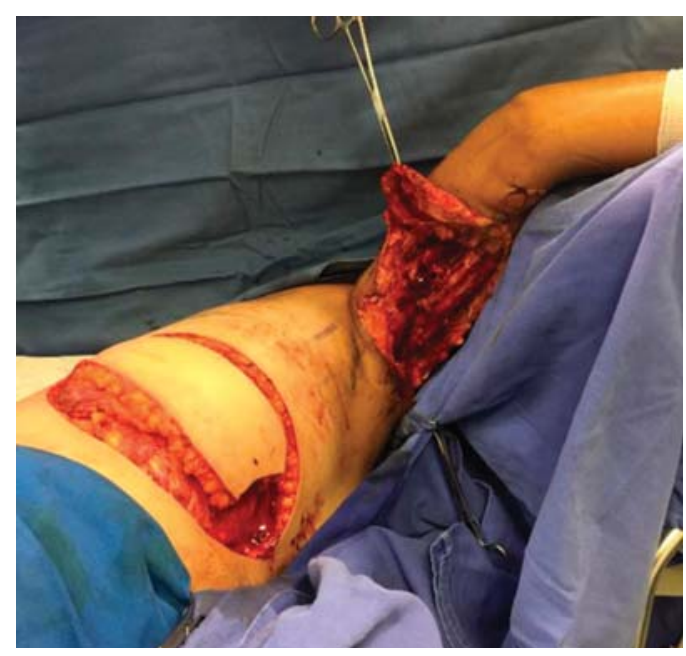

Figura 7. Sitio donador y proyección hacia el sitio receptor en la superficie medial del brazo. tendones, estructuras neurovasculares y elementos nobles. La selección de la cobertura debe proveer una superficie deslizante para las estructuras móviles y permitir la vascularidad en la zona lesionada.

La pérdida extensa de tejido blando es uno de los mayores problemas en la extremidad superior lesionada. Las pérdidas aisladas de piel se pueden tratar mediante injertos de espesor parcial si no se encuentra en prominencias óseas,

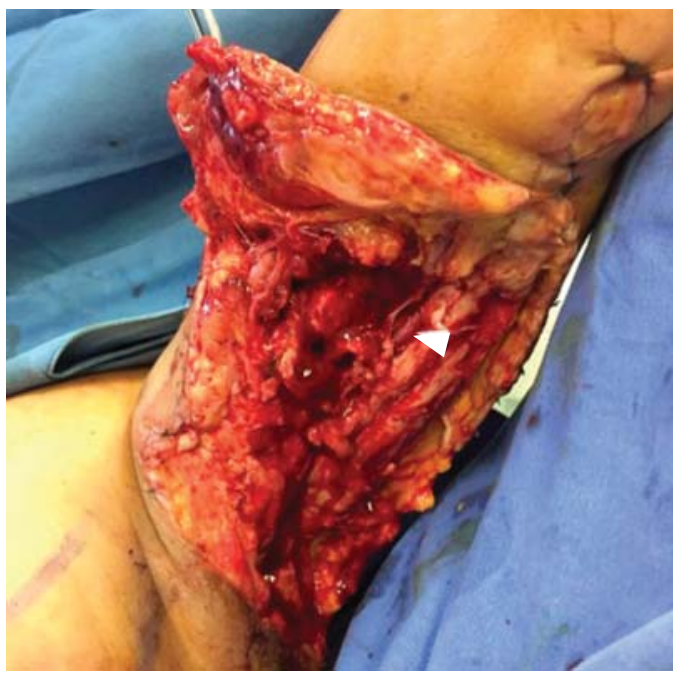

Figura 8. Defecto real de cobertura cutánea en el brazo derecho después del desbridamiento con exposición de la arteria humeral reparada (flecha).

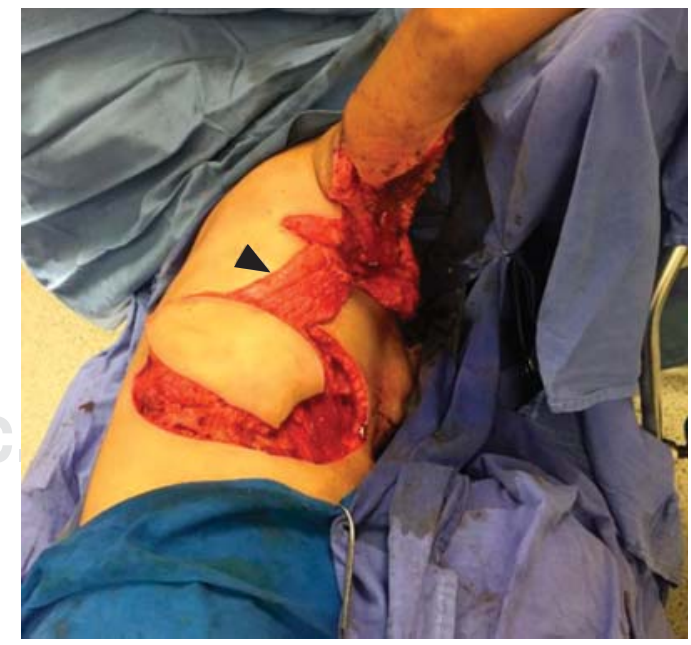

Figura 9. Levantamiento del colgajo de interpolación con isla de piel, tira de músculo dorsal ancho (flecha). 
elementos nobles o tendones expuestos. Los colgajos cutáneos de tipo aleatorio tienen una utilidad limitada incluso en defectos de tejidos blandos superficiales, debido a su movilidad restringida, bajo aporte sanguíneo y el potencial daño que hayan recibido con la lesión.

La pérdida de piel sobre una prominencia ósea o elementos nobles se puede manejar de
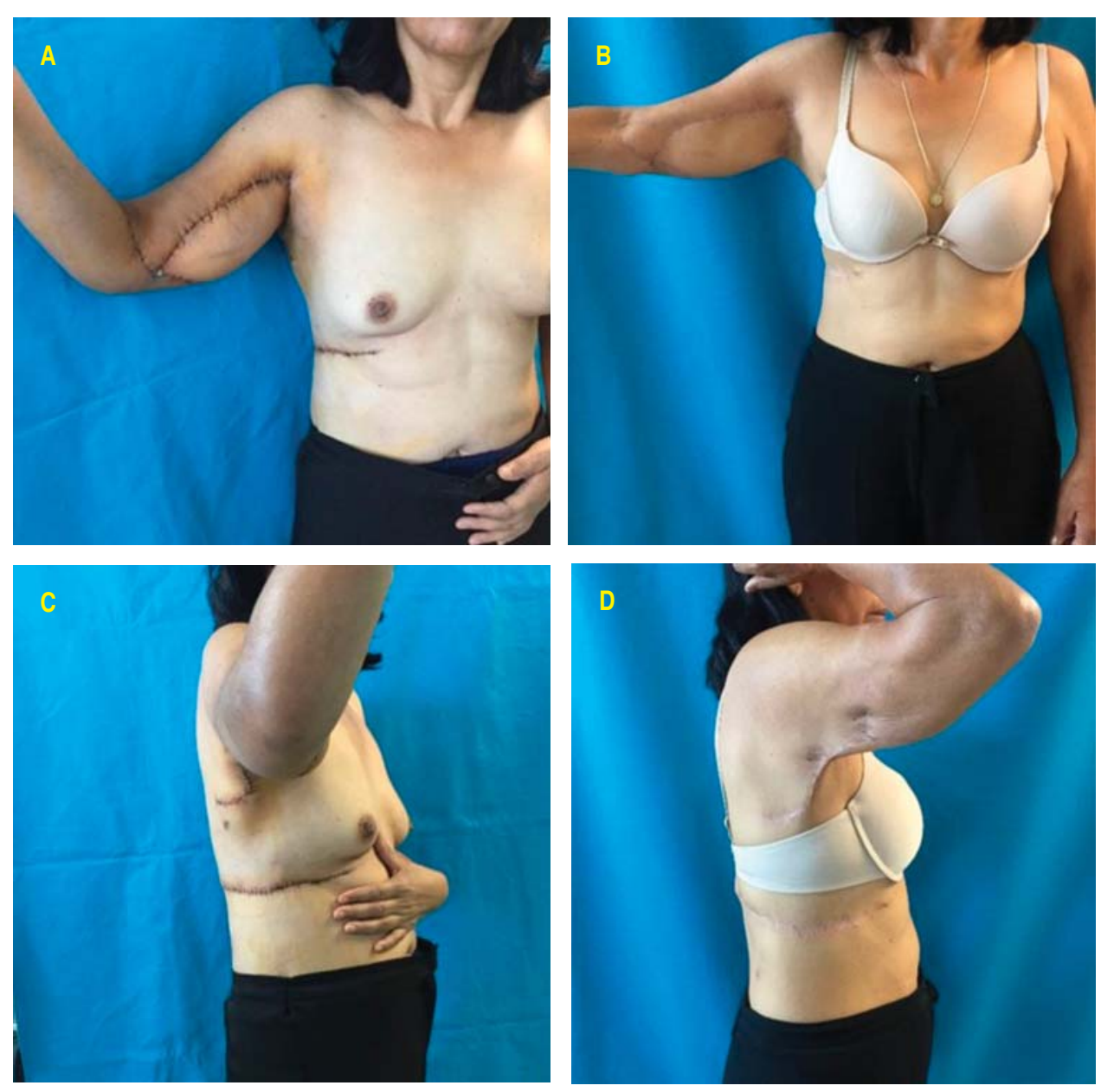

Figura 10.

Aspecto en el postoperatorio mediato (A, C y E) y comparativo a los seis meses del evento quirúrgico (B, D y F), con adecuada cobertura y vitalidad de la extremidad, sin limitación funcional significativa.
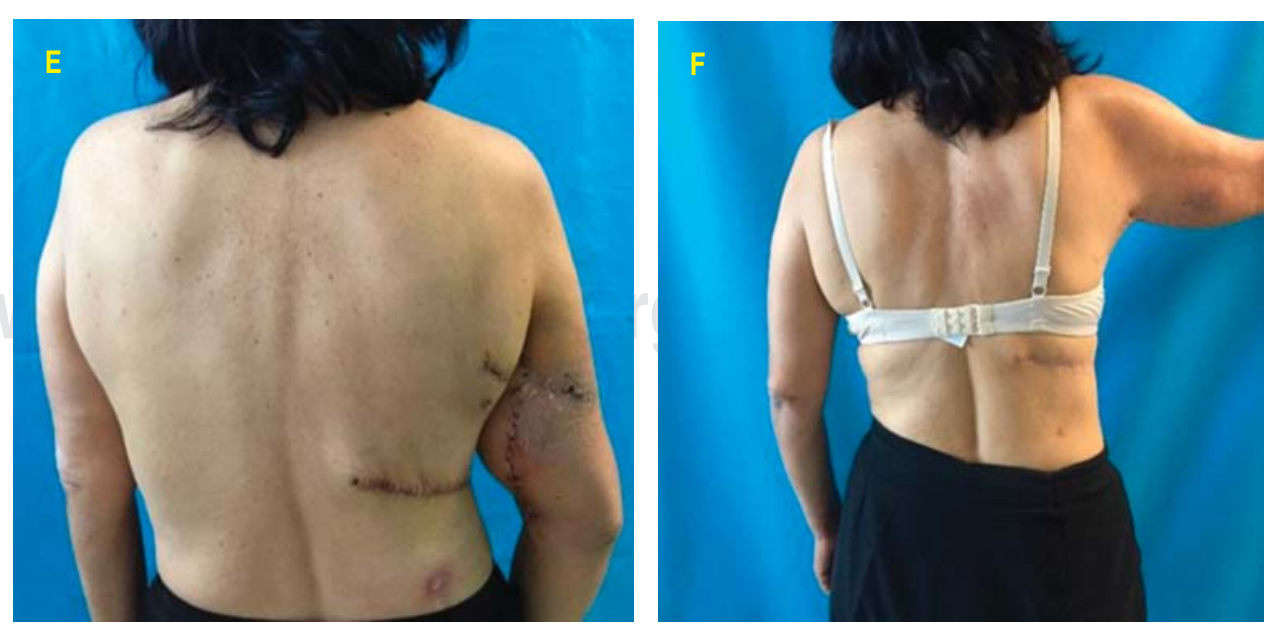
varias maneras: una aproximación simple consiste en dejar abierta la herida para cerrar por segunda intención con tejido de granulación; sin embargo, los tejidos blandos sensibles a la desecación, como los nervios, vasos y tendones, tienden a la necrosis, se promueve el tejido cicatricial y consecuentemente se compromete la función. Los colgajos musculares locales con frecuencia no son útiles por su proximidad con la zona de la lesión, la cobertura limitada que proveen y el déficit funcional resultante. Se procura evitar los colgajos distantes en dos tiempos, debido a que la inmovilización de la zona reconstruida causará rigidez articular, pero si fuera necesario, las opciones reconstructivas incluyen el colgajo inguinal pediculado, el colgajo cruzado de brazo, el colgajo acromiotorácico y el abdominal.

En las lesiones traumáticas, la necesidad de cobertura extensa, confiabilidad de la vascularidad de un colgajo y la movilización temprana requieren con frecuencia el uso de colgajos axiales, locales o regionales, colgajos pediculados distantes en un solo tiempo o colgajos libres.

El tipo de cobertura depende del sitio y la extensión del defecto, esto es especialmente importante para la cobertura de elementos nobles, así como para facilitar procedimientos reconstructivos futuros al planear una reconstrucción en etapas.

Los colgajos fasciocutáneos están recomendados cuando hay tendones expuestos, éstos facilitan la excursión de los mismos. Sin embargo, la mayoría de los colgajos fasciocutáneos no tienen una apariencia cosmética a medida que pasa el tiempo. Los principales colgajos fasciocutáneos usados incluyen el colgajo radial libre o rotacional, el colgajo lateral de brazo y el colgajo inguinal y una alternativa para los colgajos fasciocutáneos es un colgajo fascial. Los sitios donadores incluyen la fascia temporoparietal, la fascia paraescapular y la fascia radial. El colgajo fascial libre posteriormente se cubre con un injerto de espesor parcial sin mallar.

Los colgajos musculares se usan cuando existen defectos tisulares medianos a grandes. En el brazo y el codo se puede usar el músculo dorsal ancho como un colgajo pediculado de rotación en un solo tiempo. El resto de las reconstrucciones se realizan con transferencias libres de músculo utilizando el gracilis, recto abdominal, dorsal ancho o serrato anterior.

Debido a las características del defecto y los elementos expuestos, se seleccionó el colgajo dorso-epigástrico como tratamiento quirúrgico definitivo para cobertura. Éste toma como referencias anatómicas la línea vertebral, el borde inferior escapular y el borde lateral del músculo dorsal ancho, toma la rama descendente de la arteria toracodorsal $2 \mathrm{~cm}$ por dentro del borde lateral del dorsal ancho; incluye una isla cutánea por debajo del ángulo inferior escapular y se dirige hacia el surco inframamario y a la región paravertebral en sentido posterior, tomando una banda entre 5 y $7 \mathrm{~cm}$ de músculo. ${ }^{2}$

El colgajo miocutáneo de dorsal ancho está evaluado como un colgajo muy seguro y sumamente versátil y existen reportes desde 1977 de sus alcances, incluso hasta el antebrazo o hasta la región del cráneo. ${ }^{3}$ Angrigiani, ${ }^{4}$ reportó una modificación a la técnica clásica de levantamiento del colgajo de dorsal ancho al basarse únicamente en las perforantes de la rama descendente de la arteria toracodorsal, sentando las bases anatómicas en un estudio con 40 cadáveres para el colgajo denominado como dorsal ancho ahorrador de músculo. ${ }^{4}$

Saint-Cyr, ${ }^{5}$ reportó en 2009 su experiencia con 20 casos de reconstrucción mamaria con un colgajo dorsal ancho ahorrador de músculo con una isla de piel orientada transversalmente e hizo énfasis en las ventajas como la mínima morbilidad del sitio donador, baja tasa de formación de seromas, gran libertad de orientación de la isla de piel, baja incidencia de complicaciones y una cicatriz cosméticamente aceptable.

Dados los antecedentes mencionados, se hace evidente que la cobertura cutánea del miembro superior proximal es susceptible de resolver por medio del colgajo de dorsal ancho, encontrándonos con la posibilidad de realizarlo con la variante descrita como el colgajo dorsoepigástrico. ${ }^{6}$

\section{CONCLUSIÓN}

El colgajo dorso-epigástrico es una opción poco reportada en la literatura mundial combinando la técnica para ahorrar músculo, con baja morbilidad, cuya isla de piel permite brindar 
cobertura cutánea de sitios más allá de la región de la mama, donde se emplea con frecuencia con excelentes resultados funcionales y buenos resultados estéticos.

\section{REFERENCIAS}

1. Panattoni JB, Ahmed MM, Busel GA. An ABC technical algorithm to treat the mangled upper extremity: systematic surgical approach. J Hand Surg Am 2017; 42 (11): 934.e1-934.e10.

2. Haddad-Tame J, Jiménez-Muñoz Ledo G. Descripción anatómico-quirúrgica del colgajo dorsoepigástrico: una opción diferente en reconstrucción mamaria. Cir Plast Iberolatinoam 2012; 38 (1): 27-34.

3. Silverton J, Nahai F, Jurkiewicz M. The Latissimus dorsi myocutaneous flap to replace a defect on the upper arm. Br J Plast Surg 1978; 31 (1): 29-31.
4. Angrigiani C, Grilli D, Siebert J. Latissimus dorsi musculocutaneous flap without muscle. Plast Reconstr Surg 1995; 96 (7): 1608-1614.

5. Saint-Cyr M, Nagarkar $P$, Schaverien $M$ et al. The pedicled descending branch muscle-sparing Latissimus dorsi flap for breast reconstruction. Plast Reconstr Surg 2009; 123: 13-24.

6. Bektas G, Coskunfirat K, Cinpolat A. Free or pedicled thoracodorsal artery perforator flap for repair of soft tissue defect on the upper limb. Plast Reconstr Surg 2011; 128: 100.

\section{Correspondencia:}

Dr. Jesús Fernando Romero Espinosa

Av. Nicolás San Juan $s / n$,

Col. Ex-Hacienda la Magdalena,

50010, Toluca de Lerdo, Estado de México.

Teléfono: (722) 276 0860, ext. 90427

E-mail: fernandoromeromd@yahoo.com.mx 